\title{
Backstepping Control for Induction Motors with Input and Output Constraints
}

\author{
Tung Lam Nguyen \\ Department of Industrial Automation \\ University of Science and Technology \\ Hanoi, Vietnam \\ lam.nguyentung@hust.edu.vn
}

\author{
Thanh Ha Vo \\ Department of Electrical Engineering \\ University of Transportation and \\ Communications, Hanoi, Vietnam \\ vothanhha.ktd@utc.edu.vn
}

\author{
Nam Duong Le \\ Department of Electrical Engineering \\ Quy Nhon University \\ Quy Nhon, Vietnam \\ lenamduong@qnu.edu.vn
}

\begin{abstract}
In practice, the applied control voltage for an induction motor drive system fed by a voltage source inverter has a limit depending on the DC bus capacity. In certain operations such as accelerating, the motor might require an excessively high voltage value that the DC bus cannot supply. This paper presents a control solution for the bounded control input problem of the induction motor system by flexibly combining a hyperbolic tangent function in a backstepping control design procedure. In addition, the Barrier Lyapunov function is also employed to force speed tracking error in a defined value. The closed-loop system stability is proven, and the proposed control is verified through numerical simulations.
\end{abstract}

Keywords-backstepping; Barrier Lyapunov funtion; induction motor; FOC

\section{INTRODUCTION}

Induction motors have been serving as a major workforce in various industrial applications $[1,2]$ due to their robustness and ease of maintenance. Despite the fact that technologies used in induction motor drive systems are well-established, the drive system still draws control researchers' attention due to its complicated dynamical properties $[3,5]$. In the two most common induction motor drive control techniques, Flux Oriented Control (FOC) [6] based schemes are widely used when compared to Direct Torque Control (DTC) structure [7]. FOC renders the induction motor as a direct current motor in terms of decoupling torque producing and flux forming process. There have been many attempts to control the induction motor based on FOC, from classical PID control [2] to advance nonlinear strategies including model predictive control [8], sliding mode control [9], fuzzy-neural approach [10], and genetic algorithm [11]. Thanks to its systematic design and the ability to cope with system nonlinearities, backstepping method is intensively used in the induction motor drive. Authors in [12] successfully employed backstepping integrated with a high-gain observer for stabilizing the motor drive without information on the rotor speed, flux, and load torque. In order to compensate system uncertainties, backstepping was combined with a recurrent neural network to enhance tracking performance in induction servo systems [13]. A similar approach can be found in [14] where a radial basis function neural network was used. The proposed control guarantees system stability and bounded signals. Exploiting the robustness of sliding mode control, authors in [15] designed a backstepping sliding mode control for dealing with lumped uncertainties in linear induction motor drives. The effectiveness of the proposed control is verified numerically and experimentally. In [16], adaptive backstepping control supported by a fuzzy system for integral action was developed for a linear induction motor. Simulation study showed the control ability to cope with parameter variations and load disturbances. In the quest of compensating system mechanical parameters such as unknown viscous coefficient and load torque, an adaptive backstepping algorithm was designed in [17]. Other applications of backstepping control in induction motor drive can be seen in $[18,19]$.

The aforementioned researches mainly focus on ways to improve the dynamical responses of the induction motor drive closed-loop system regardless the limitations of the control inputs. It is clearly that in certain circumstances, the motor might require exceeded voltage value that the DC bus cannot supply. If the required voltage is not satisfied, it results in system performance degradation. In this paper, a method is introduced to tackle the problem by manipulating backstepping control with the assistance of a virtual control defined through a hyperbolic tangent function for limiting the control input in a specified value determined by the capacity of the DC bus. In addition, the paper also integrates Barrier Lyapunov function in the design steps in order to force the speed tracking error falling in a desired range.

\section{MATHEMATICAL MODEL FORMULATION}

The mathemathetical model of the induction motor is well defined, for more detailed derivation please refer to [20]. The induction motor model in the $d$-q reference frame is obtained as in (1) where: $\sigma=1-\frac{L_{m}^{2}}{L_{s} L_{r}}$ is the leakage factor, $T_{s}=\frac{L_{s}}{R_{s}}$ the stator time constant, $T_{r}=\frac{L_{r}}{R_{r}}$ the rotor time constant, $k_{r}=\frac{L_{m}}{L_{r}}$, $r_{\sigma}=R_{s}+R_{r} k_{r}^{2}, T_{\sigma}^{\prime}=\frac{\sigma L_{\sigma}}{r_{\sigma}}, \omega_{s}=\omega+\frac{L_{m}}{T_{r}} \frac{i_{s d}}{\psi_{r d}}$ the slip estimation, $\omega$ is the mechanical rotor speed, $z_{p}$ is the number of pole pairs, $J$ is the rotor and load lumped inertia, $T_{L}$ the load torque, $\psi_{r d}$ 
the rotor flux, and $L_{m}, L_{r}, L_{s}$ : mutual, rotor, and stator inductance.

$$
\left\{\begin{aligned}
\frac{d i_{s d}}{d t}= & -\left(\frac{1}{\sigma T_{s}}+\frac{1-\sigma}{\sigma T_{r}}\right) i_{s d}+\omega_{s} i_{s q}+\frac{1-\sigma}{\sigma T_{r}} \psi_{r d}^{\prime}+\frac{1}{\sigma L_{s}} u_{s d} \\
\frac{d i_{s q}}{d t}= & -\omega_{s} i_{s d}-\left(\frac{1}{\sigma T_{s}}+\frac{1-\sigma}{\sigma T_{r}}\right) i_{s q}-\frac{1-\sigma}{\sigma} \omega \psi_{r d}^{\prime} \\
& +\frac{1-\sigma}{\sigma T_{r}} \psi_{r q}^{\prime}+\frac{1}{\sigma L_{s}} u_{s q} \\
\frac{d \psi_{r d}^{\prime}}{d t}= & \frac{1}{T_{r}} i_{s d}-\frac{1}{T_{r}} \psi_{r d}^{\prime}+\left(\omega_{s}-\omega\right) \psi_{r q}^{\prime} \\
m_{M}= & \frac{3}{2} z_{p} \frac{L_{m}^{2}}{T_{r}} \psi_{r d}^{\prime} i_{s q}=-\frac{3}{2} z_{p}(1-\sigma) L_{s} \psi_{r d}^{\prime} i_{s q}
\end{aligned}\right.
$$

The first two equations characterize motor current dynamics. The last two equations denote motor flux forming process and equation of motion. It can be observed that the induction motor given in (1) is a coupled and nonlinear system. The block diagram representation of the induction motor is given in Figure 1.

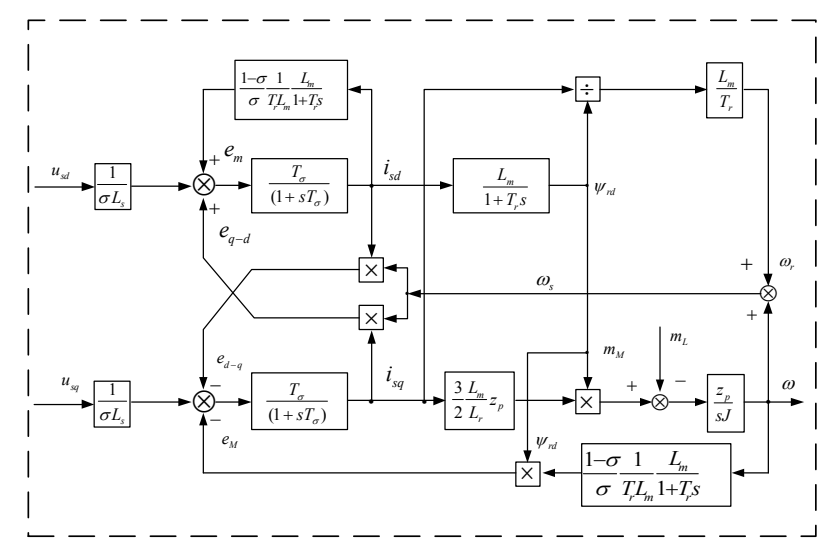

Fig. 1. Structure of the induction motor in $d q$-coordinates.

\section{BACKSTEPPING CONTROLLER DESIGN WITH CONTROL INPUT AND OUTPUT CONSTRAINS}

\section{A. Magnetic Flux Control Design}

The control objective is to drive the motor magnetic flux to a desired value in such a way that the tracking error stays in a predefined range. In order to achieve this objective, the tracking error is defined as follows:

$$
z_{1}=x_{1}-\varphi_{r d r e f}^{\prime}
$$

and a Lyapunov candidate function is:

$$
V_{1}=\frac{1}{2} \log \frac{k_{b}^{2}}{k_{b}^{2}-z_{1 d}^{2}}
$$

Taking the time derivative of $V_{l}$ gives:

$$
\dot{V}_{1}=\frac{z_{1 d}\left(x_{2}-\dot{q}_{d}\right)}{k_{b}^{2}-z_{1 d}^{2}}
$$

At this point, $x_{2}$ is considered as a control input, the error between $x_{2}$ and the desired control value is defined as:

$$
z_{2}=x_{2}-\alpha_{1}
$$

where $a_{l}$ is the virtual control. Substituting (5) into (4) gives:

$$
\dot{V}_{1}=\frac{z_{1 d}\left(z_{2}+a_{1}-\dot{q}_{d}\right)}{k_{b}^{2}-z_{1 d}^{2}}
$$

Equation (6) suggests that the virtual control can be selected as:

$$
a_{1}=c_{1} z_{1 d}+x_{2}+\frac{\dot{q}_{d}-\dot{x}_{1}}{\left(k_{b}^{2}-z_{1 d}^{2}\right)}
$$

The virtual control renders $\dot{V}_{1}$ as:

$$
\dot{V}_{1}=-c_{1} z_{1 d}^{2}+z_{1 d} z_{2}
$$

To deal with the coupling term $z_{1} z_{2}$ and force $z_{2}$ to zero, we propose a Lyapunov candidate function as:

$$
V_{2}=\frac{1}{2} z_{2 d}^{2}+V_{1}
$$

The derivative of $V_{2}$ will have the following form:

$$
V_{2}=-c_{1} z_{1 d}^{2}+z_{1 d} z_{2 d}+z_{2 d} \dot{z}_{2 d}
$$

Taking the derivative of (5) we have:

$$
\dot{z}_{2}=-c_{1} \dot{z}_{1}-\frac{\left(\ddot{q}_{d}-\ddot{x}_{1}\right)\left(k_{b 1}^{2}-z_{1 d}^{2}\right)-2 z_{1 d}^{2} \dot{z}_{1}}{\left(k_{k 1}^{2}-z_{1 d}^{2}\right)^{2}}
$$

Substituting the first and second equations (10) to (11) results in:

$$
\begin{aligned}
\dot{z}_{2}= & \frac{1}{T_{r}\left(k_{b 1}^{2}-z_{1 d}^{2}\right)}\left(-\frac{1}{T_{\sigma}} x_{2}+\omega_{s} x_{1}+\frac{1-\sigma}{\sigma T_{\sigma}} x_{1}+\frac{1}{\sigma T_{\sigma}} u_{s d}\right) \\
& -\frac{1}{T_{r}\left(k_{b 1}^{2}-z_{1 d}^{2}\right)}\left(\frac{1}{T_{\sigma}} x_{2}-\frac{1}{T_{r}} x_{1}\right)+c_{1}\left(\frac{1}{T_{r}} x_{2}-\frac{1}{T_{r}} x_{1}-\dot{q}_{d}\right) \\
& +\frac{2 z_{1 d}^{2}}{\left(k_{b 1}^{2}-z_{1 d}^{2}\right)^{2}}\left(\frac{1}{T_{r}} x_{2}-\frac{1}{T_{r}} x_{1}-\dot{q}_{d}\right)-\ddot{q}_{d}
\end{aligned}
$$

From (10) and (12) the control signal can be achieved guaranteeing $x_{1}$ converges to $d q$ with the dynamical error confined in a range defined by $k_{b}$. Another control objective is to specify the control input subject to a limitation. It is necessary to consider input constrains in the control design since the applied voltage is supplied from an inverter whose output voltage is practicallye limited. Toward this end, the limitation of the output voltage is described as a tangent function.

$$
u_{s d} \equiv g(v)=u_{M} \tanh \left(\frac{v}{u_{M}}\right)
$$

where $u_{M}$ is the control limit. The design of $u_{s d}$ is passed to the construction of $\vartheta$. Equation (13) results in: 


$$
\dot{g}(v)=\frac{\partial g(v)}{\partial v} \dot{v}
$$

The control design of $u_{s d}$ is subject to $u_{s d} \leq u_{M}$ is a shift to a task of finding a virtual signal $U_{l}$ defined by:

$$
\dot{v}=\frac{\partial g(g)^{-1}}{\partial v} U_{1}
$$

To proceed we define:

$$
z_{3}=u_{s d}-\alpha_{2} \equiv g(v)-\alpha_{2}
$$

From (12) and (16) the virtual control $a_{2}$ can be selected as:

$$
\begin{aligned}
& \alpha_{2}=-\sigma L_{\sigma} T_{r}\left(k_{b 1}^{2}-z_{1}^{2}\right)\left(z_{1}+\frac{1}{T_{r}\left(k_{b 1}^{2}-z_{1}^{2}\right)}\left(-\frac{x_{2}}{T_{\sigma}}+\omega_{s} x_{1}\right.\right. \\
& +\frac{1-\sigma}{\sigma T_{r}} x_{1}-\frac{1}{T_{r}\left(k_{b 1}^{2}-z_{1}^{2}\right)}\left(\frac{1}{T_{r}} x_{2}-\frac{1}{T_{r}} x_{1}\right) \\
& +c_{1}\left(\frac{1}{T_{r}} x_{2}-\frac{1}{T_{r}} x_{1}-\dot{q}_{d}\right)+\frac{2 z_{1}^{2}}{\left(k_{b 1}^{2}-z_{1}^{2}\right)^{2}}\left(\frac{1}{T_{r}} x_{2}-\frac{1}{T_{r}} x_{1}-\dot{q}_{d}\right) \\
& \left.-\ddot{q}_{d}+c_{2} z_{2}\right)
\end{aligned}
$$

Virtual control $a_{2}$ renders $\dot{V}_{2}$ as:

$$
\dot{V}_{2}=-c_{1} z_{1}^{2}-c_{2} z_{2}^{2}+\frac{1}{\left(k_{b 1}^{2}-z_{1}^{2}\right) T_{r} \sigma L_{s}} Z_{2} Z_{3}
$$

In order to remove the coupling term related to $z_{2} z_{3}$ and drive $g(v)$ to track $a_{2}$, a Lyapunov candidate function is proposed as follows:

$$
V_{3}=\frac{1}{2} z_{3}^{2}+V_{2}
$$

The derivative of (19) yields:

$$
\dot{V}_{3}=-c_{1} z_{1}^{2}-c_{2} z_{2}^{2}+\frac{1}{\left(k_{b 1}^{2}-z_{1}^{2}\right) T_{r} \sigma L_{s}} z_{2} z_{3}+z_{3} \dot{z}_{3}
$$

Taking the derivative of (16) and substituting the result into (20), we can finally get the virtual control that guarantees bounded control input as:

$$
U_{1}=-\frac{1}{\left(k_{b 1}^{2}-z_{1}^{2}\right) T_{r} \sigma L_{s}} z_{2}+\dot{a}_{2}-c_{3} z_{3}
$$

Substituting the proposed control into (20) gives:

$$
\dot{V}_{3}=-c_{1} z_{1}^{2}-c_{2} z_{1}^{2}-c_{3} z_{3}^{2} \leq 0
$$

and the design process for magnetic flux is completed.

\section{B. Speed Control Design}

The speed control design with input and output constrains is carried out in the same manner as in the previous section. For the sake of abstract presentation, control design steps are summarized in this section as follows:

$$
t_{1}=x_{3}-\dot{\omega}_{r e f}
$$

$$
\begin{gathered}
\beta_{1}=-d_{1} t_{1}+x_{4}-\frac{\dot{x}_{2}-\dot{\omega}_{r e f}}{k_{b 1}^{2}-t_{1}^{2}} \quad(24) \\
t_{2}=x_{4}-\beta_{1} \quad(25) \\
\beta_{2}=-\frac{J \sigma L_{s}\left(k_{b 1}^{2}-t_{1}^{2}\right)}{k_{m} x_{1}}\left(\frac{k_{m} x_{1}}{J\left(k_{b 1}^{2}-t_{1}^{2}\right)}\left(-\omega_{s} x_{2}-\frac{x_{4}}{T_{\sigma}}-\frac{1-\sigma}{\sigma} \omega x_{1}\right)\right. \\
+\frac{k_{m} x_{4}}{J\left(k_{b 1}^{2}-t_{1}^{2}\right)}\left(\frac{1}{T_{r}} x_{2}-\frac{1}{T_{r}} x_{1}\right)-\frac{\dot{\omega}_{r e f}}{\left(k_{b 1}^{2}-t_{1}^{2}\right)}+t_{1} \\
\left.+\frac{2 t_{1}^{2}}{\left(k_{b 1}^{2}-t_{1}^{2}\right)^{2}}\left(\frac{k_{m} x_{1} x_{4}}{J}-\dot{\omega}_{r e f}\right)+d_{1}\left(\frac{k_{m} x_{1} x_{4}}{J}-\dot{\omega}_{r e f}\right)+d_{2} t_{2}\right) \\
t_{3}=u_{s q}-\beta_{2}=g(v)-\beta_{2} \quad(27) \\
U_{2}=-\frac{k_{m} x_{1}}{\left(k_{b 1}^{2}-t_{1}^{2}\right) J \sigma L_{s}} t_{2}+\dot{\beta}_{2}-d_{3} t_{3}
\end{gathered}
$$

where $\beta_{1}, \beta_{2}$ are virtual controls and $t_{1}, t_{2}, t_{3}$ are the backstepping design errors in each step. The control signal guaranteeing bounded input and output is $U_{2}$.

\section{SimUlation RESUlts}

\section{A. Settings}

Simulations were conducted on an IM machine with the structure control for induction motor shown in Figure 2. The space vector modulation is used for the inverter part. $R_{\psi}, R_{\omega}$, and $R_{I}$, are flux, speed, and $d q$-current controllers, respectively. Simulation parameters are given in Table I. In the simulation, two control schemes were implemented: conventional and input-output embedded backstepping controls.

TABLE I. SIMULATION PARAMETERS

\begin{tabular}{|c|c|c|}
\hline Rated power & $P_{\text {nom }}$ & $2.2 \mathrm{~kW}$ \\
\hline Speed motor & $n_{\text {nom }}$ & $2880 \mathrm{prm}$ \\
\hline Rated phase current & $I_{\text {nom }}$ & $4.7 \mathrm{~A}_{\mathrm{RMS}}$ \\
\hline Number of pole pairs & $z_{p}$ & 1 \\
\hline Rotor resistance & $R_{r}$ & $0.42 \Omega$ \\
\hline Stator resistance & $R_{s}$ & $0.37 \Omega$ \\
\hline Rotor inductance & $L_{r}$ & $34.25 \mathrm{mH}$ \\
\hline Stator inductance & $L_{s}$ & $34.41 \mathrm{mH}$ \\
\hline Mutual inductance & $L_{m}$ & $33.1 \mathrm{mH}$ \\
\hline Total inertia & $J$ & $0.001 \mathrm{kgm}^{2}$ \\
\hline
\end{tabular}

\section{B. Simulation Procedure}

At $t=0 s$, magnetic current is created and at $t=2 s$ the system speeds up to $1200 \mathrm{rpm}$. In the simulation scenario, a sudden torque with rated value of $1.5 \mathrm{Nm}$ is applied on the motor shaft. The results of the simulation of stator current and speed controllers using conventional backstepping control method and backstepping with control input and output constrains are shown in Figures 3-8 where (a) represents the response of conventional backstepping and (b) represents the backstepping with input and output constraints. The proposed backstepping controller is applied to the induction motor. The coefficients are chosen as: $c_{1}=1000, c_{2}=1000, c_{3}=5150, c_{4}=1000, d_{1}=500$, $d_{2}=500, d_{3}=1000$, and $d_{4}=500$. 


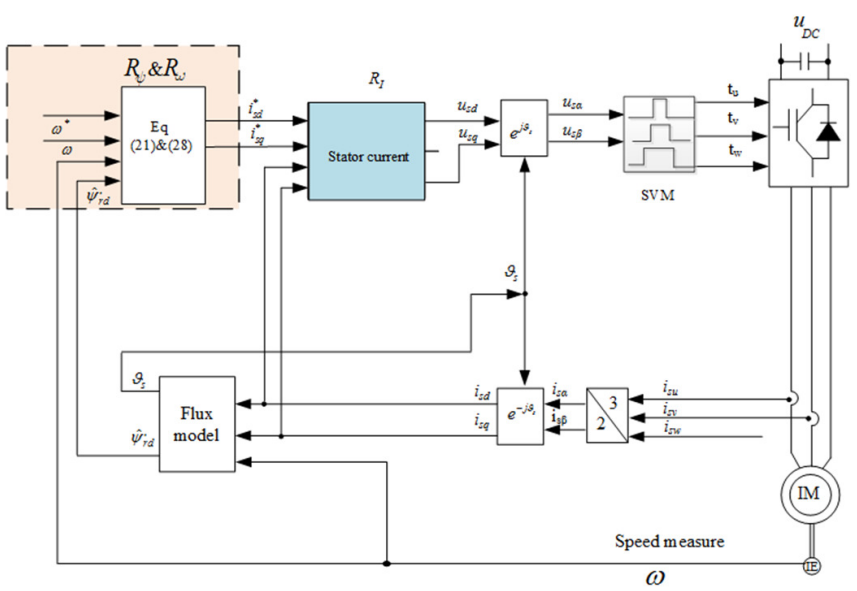

Fig. 2. Backstepping control with output and input contraints.

In the simulation result, the control signal constraint is selected as:

$$
U_{s}=\sqrt{u_{s d}^{2}+u_{s q}^{2}} \leq 160 \mathrm{~V}
$$

Constraints on $d q$ are determined according to rectangular approximation:

$$
u_{s q}^{\max }=\alpha \frac{V_{d c}}{\sqrt{3}} \text { and } u_{s d}^{\max }=\sqrt{1-\alpha^{2}} \frac{V_{d c}}{\sqrt{3}}
$$

where $V_{d q}=300 \mathrm{~V}$ and $a=0.8$. This condition implies that control inputs must satisfy:

$$
\left|u_{s q}\right| \leq u_{s q}^{\max } \text { and }\left|u_{s d}\right| \leq u_{s d}^{\max }
$$

The designed controller can also limit the system's output through the value $k_{b}$. This helps us to control the overshoot of the system. In the simulation, we set the value $k_{b}=0.1$.

(a)

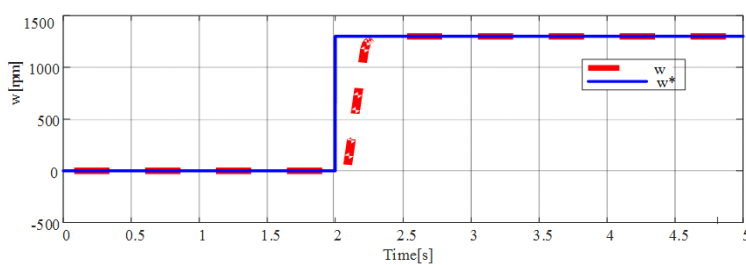

(b)

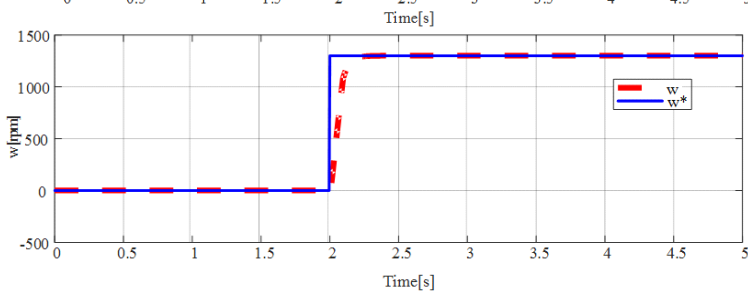

Fig. 3. Speed response.

For the system controlled by the conventional backstepping method, we set the dc bus voltage to $V_{d c}=300 \mathrm{~V}$. This implies that there is no hard limit applied in this case. On the contrary, the dc bus voltage is restricted to $160 \mathrm{~V}$ when the induction motor drive system is regulated by backstepping control with input and output constraints. In both cases, simulation results show that the two approaches provide good tracking performance with fast response time as can be seen in Figure 3.

(a)

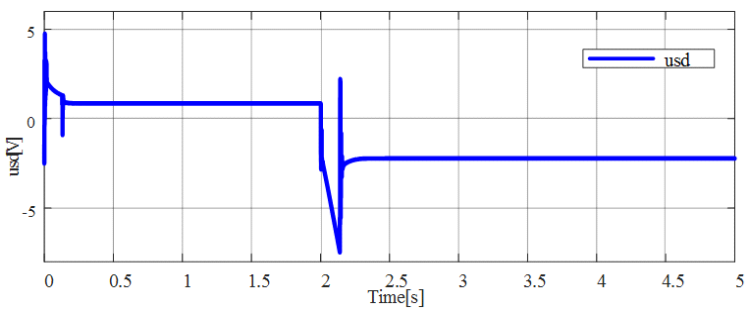

(b)

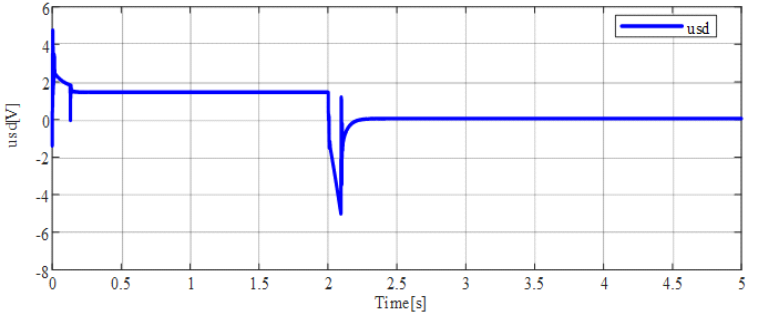

Fig. 4. Voltage response $u_{s d}$

(a)

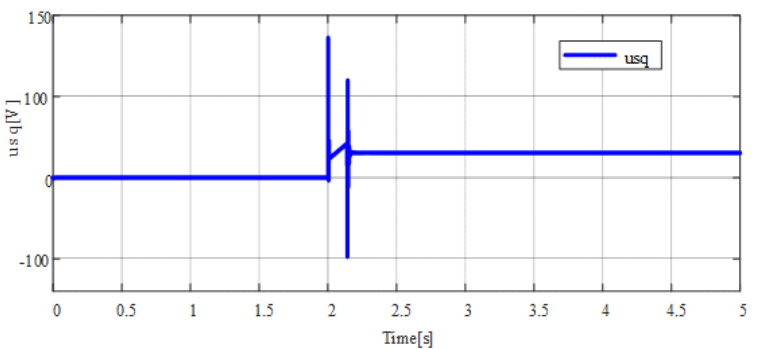

(b)

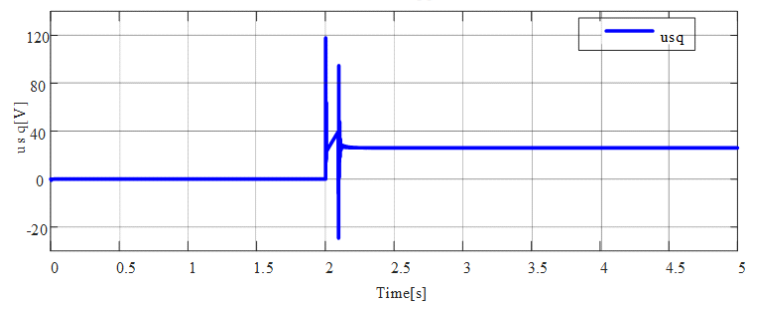

Fig. 5. Voltage response $u_{s q}$.

(a)

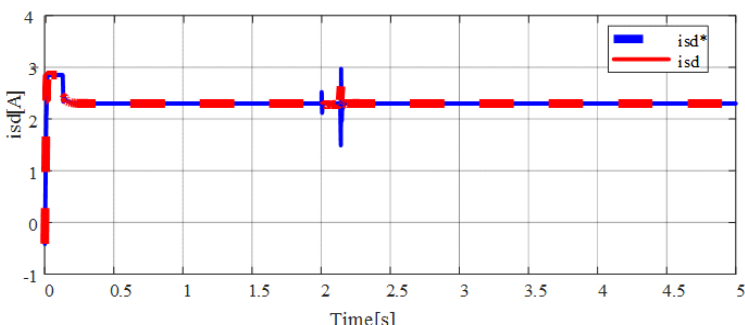

(b)

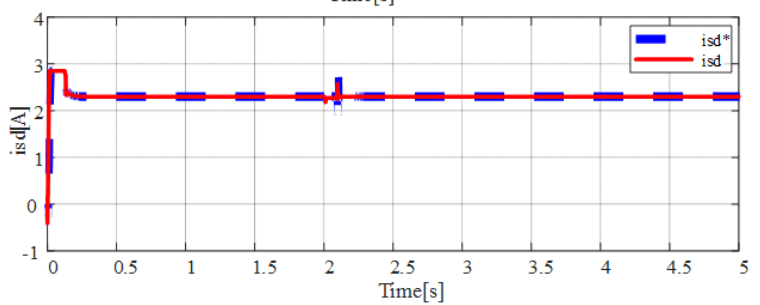

Fig. 6. Stator current responses $i_{s d}$. 
(a)

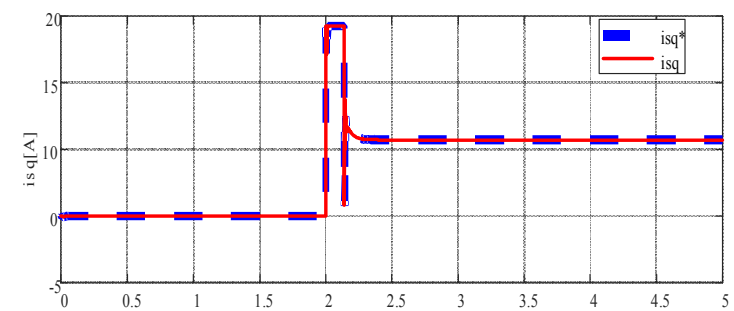

(b)

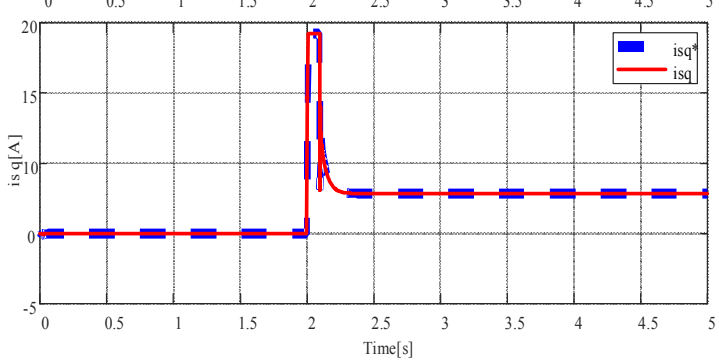

Fig. 7. Stator current responses $i_{s q}$

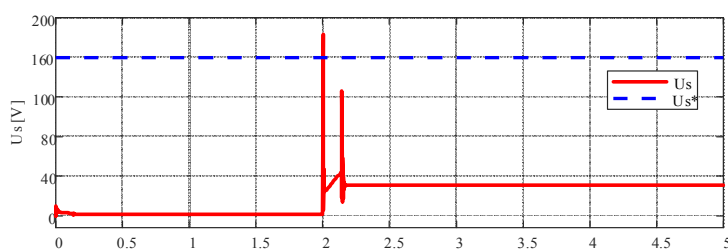
me[s

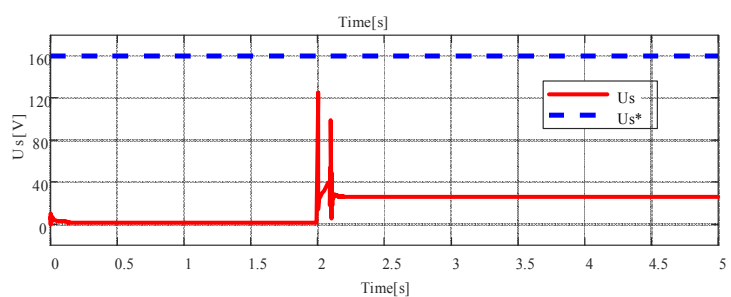

Fig. 8. Voltage $U_{s}$ response.

It is noted that at $2 \mathrm{~s}$ the motor accelerates to $1200 \mathrm{rpm}$. This speeding action requires a considerably large quadrature current and voltage (Figures 4(a), 5(a), 6(a), and 7(a)), resulting in $U_{s}$ reaching $180 \mathrm{~V}$ in the case of the conventional method as shown in Figure 8(a). Meanwhile, due to the fact that the control inputs are tied to $160 \mathrm{~V}$, the $U_{s}$ measured values when the backstepping with input and output limitation action is suppressed well below 120V (Figures 4-8(b)). The results show technical meaning when the system requires large control input when fast accelerating or deaccelerating in the face of limited dc bus capacity. The speed tracking also indicates that the overshoot remains in the bounded set specified by $k_{b}=0.1$. We see that the controller designed by this method helps the drive system respond well in accordance with the set values. However, the disadvantage of this method is that it is difficult to select the optimal coefficients for the controller, the design process of calculating control signals requires many derivative steps leading to a large volume of calculations.

\section{CONCLUSION}

The paper proposes a control mechanism backboned by backstepping control to avoid voltage saturation in induction motor drive systems. The hyperbolic tangent is embedded in the control design to deal with the voltage saturation problem. This approach differs from other works where either torque producing or flux forming voltage is sacrificed when the input voltage enters the saturation zone. The simulation results show that the control can suppress the control input voltage in the prescribed domain while maintaining the tracking error due to the help of the barrier Lyapunov function. In future research, we aim at deploying the proposed control in an experimental rig.

\section{REFERENCES}

[1] X. Shi, H. Li, and J. Huang, "A Practical Scheme for Induction Motor Modelling and Speed Control," International Journal of Control and Automation, vol. 7, pp. 113-124, Apr. 2014, doi: 10.14257/ijca.2014.7.4.11.

[2] T. M. Chikouche, A. Mezouar, T. Terras, and S. Hadjeri, "Variable Gain PI Controller Design For Speed Control of a Doubly Fed Induction Motor Using State-Space Nonlinear Approach," Engineering, Technology \& Applied Science Research, vol. 3, no. 3, pp. 433-439, Jun. 2013.

[3] "A robust sensorless output feedback controller of the induction motor drives: new design and experimental validation," International Journal of Control, vol. 83, no. 3, pp. 484-497, doi: 10.1080/00207170903193474.

[4] V. T. Ha, V. H. Phuong, N. T. Lam, and N. P. Quang, "A dead-beat current controller based wind turbine emulator," in 2017 International Conference on System Science and Engineering (ICSSE), Ho Chi Minh City, Vietnam, Jul. 2017, pp. 169-174, doi: 10.1109/ICSSE.2017.8030859.

[5] V. T. Ha, N. T. Lam, V. T. Ha, and V. Q. Vinh, "Advanced control structures for induction motors with ideal current loop response using field oriented control," International Journal of Power Electronics and Drive Systems (IJPEDS), vol. 10, no. 4, pp. 1758-1771, Dec. 2019.

[6] J. Zhang et al., "Integrated design of speed sensorless control algorithms for induction motors," in 2015 34th Chinese Control Conference (CCC), Jul. 2015, pp. 8678-8684, doi: 10.1109/ChiCC.2015.7261011.

[7] M. K. Sahu, A. K. Panda, and B. P. Panigrahi, "Direct Torque Control for Three-Level Neutral Point Clamped Inverter-Fed Induction Motor Drive," Engineering, Technology \& Applied Science Research, vol. 2, no. 2, pp. 201-208, Apr. 2012.

[8] S. M. Kazraji and M. B. B. Sharifian, "Model predictive control of linear induction motor drive," in IECON 2017 - 43rd Annual Conference of the IEEE Industrial Electronics Society, Oct. 2017, pp. 3736-3739, doi: 10.1109/IECON.2017.8216635.

[9] C. Regaya, A. Zaafouri, and A. Chaari, "A New Sliding Mode Speed Observer of Electric Motor Drive Based on Fuzzy-Logic," Acta Polytechnica Hungarica, vol. 11, pp. 219-232, Feb. 2014, doi: 10.12700/APH.11.03.2014.03.14.

[10] M. Denai and S. Attia, "Fuzzy and neural control of an induction motor," International Journal of Applied Mathematics and Computer Science, vol. 12, pp. 221-233, Jan. 2002.

[11] M. Chebre, A. Meroufel, and Y. Bendaha, "Speed Control of Induction Motor Using Genetic Algorithm-based PI Controller," Acta Polytechnica Hungarica, vol. 8, no. 6, pp. 141-153, Jan. 2011.

[12] I. Haj Brahim, S. Hajji, and A. Chaari, "Backstepping Controller Design using a High Gain Observer for Induction Motor," International Journal of Computer Applications, vol. 23, no. 3, pp. 1-6, Jun. 2011, doi: $10.5120 / 2873-3730$.

[13] C. M. Lin and C. F. Hsu, "Recurrent-neural-network-based adaptivebackstepping control for induction servomotors," IEEE Transactions on Industrial Electronics, vol. 52, no. 6, pp. 1677-1684, Dec. 2005, doi: 10.1109/TIE.2005.858704.

[14] J. Yu, Y. Ma, B. Chen, H. Yu, and S. Pan, "Adaptive neural position tracking control for induction motors via back stepping," International Journal of Innovative Computing, Information and Control, vol. 7, no. 7, pp. 4503-4516, Jul. 2011. 
[15] F.-J. Lin, P.-H. Shen, and S.-P. Hsu, "Adaptive backstepping sliding mode control for linear induction motor drive," IEE Proceedings Electric Power Applications, vol. 149, no. 3, pp. 184-194, May 2002, doi: 10.1049/ip-epa:20020138.

[16] I. K. Bousserhane, A. Hazzab, R. Mostefa, B. Mazari, and M. Kamli, "Mover position control of linear induction motor drive using adaptive backstepping controller with integral action," Tamkang Journal of Science and Engineering, vol. 12, pp. 17-28, Mar. 2009.

[17] H. T. Lee, "Adaptive PC-based backstepping position control of induction motor," International Journal of Power Electronics, vol. 3, no. 2, p. 156, 2011, doi: 10.1504/IJPELEC.2011.038891.

[18] M. Moutchou, A. Abbou, and H. Mahmoudi, "MRAS-based sensorless speed backstepping control for induction machine, using a flux sliding mode observer," Turkish Journal of Electrical Engineering and Computer Sciences, vol. 23, pp. 187-200, Jan. 2015, doi: 10.3906/elk1208-50.

[19] M. Morawiec, "Dynamic variables limitation for backstepping control of induction machine and voltage source converter," Archives of Electrical Engineering, vol. 61, no. 3, pp. 389-410, 2012, doi: 10.2478/v10171012-0031-1.

[20] N. P. Quang and J.-A. Dittrich, Vector Control of Three-Phase AC Machines: System Development in the Practice, 2nd ed. Berlin Heidelberg: Springer-Verlag, 2015. 